\title{
DETECTION OF HIGH-IMPEDANCE ARCING FAULTS IN RADIAL DISTRIBUTION DC SYSTEMS
}

\author{
Marcelo C. González \\ Cleveland State University \\ Department of Electrical Engineering \\ Cleveland, $\mathrm{OH} 44115$
}

\author{
Robert M. Button \\ Technology Product Manager \\ NASA Glenn Research Center \\ Cleveland, $\mathrm{OH} 44135$
}

\begin{abstract}
High voltage, low current arcing faults in DC power systems have been researched at the NASA Glenn Research Center in order to develop a method for detecting these "hidden faults", in-situ, before damage to cables and components from localized heating can occur. A simple arc generator was built and high-speed and low-speed monitoring of the voltage and current waveforms, respectively, has shown that these high impedance faults produce a significant increase in high frequency content in the DC bus voltage and low frequency content in the DC system current.

Based on these observations, an algorithm was developed using a high-speed data acquisition system that was able to accurately detect high impedance arcing events induced in a single-line system based on the frequency content of the DC bus voltage or the system current. Next, a multi-line, radial distribution system was researched to see if the arc location could be determined through the voltage information when multiple "detectors" are present in the system. It was shown that a small, passive LC filter was sufficient to reliably isolate the fault to a single line in a multi-line distribution system. Of course, no modification is necessary if only the current information is used to locate the arc. However, data shows that it might be necessary to monitor both the system current and bus voltage to improve the chances of detecting and locating high impedance arcing faults.
\end{abstract}

\section{INTRODUCTION}

As future NASA programs and missions greatly increase their required electrical power, the move to higher and higher distribution voltages becomes a necessity. Programs such as the reusable launch vehicle (RLV) and more electric aircraft will push electric distribution in the $500 \mathrm{~kW}$ to $1 \mathrm{MW}$ range. NASA's new Prometheus Program seeks to develop a $100 \mathrm{~kW}+$ space vehicle before the end of the decade, and commercial communication satellites are continuing their upward trend in power levels to over $20 \mathrm{~kW}$ of on-board power. All these trends require significant increases in the distribution voltages in order for these systems to remain viable.
Current state of the art for space electrical power systems is the International Space Station. With a total energy generation capacity of $75 \mathrm{~kW}$ and a highly channelized topology, the nominal distribution voltage is 160VDC. The proposed high power systems enumerated above will require distribution voltages starting at $270 \mathrm{VDC}$ on up past $600 \mathrm{VDC}$. Not only will these high voltage distribution systems pose challenges to electrical component manufacturers, but they also introduce a new potential fault that must now be accounted for - electrical arcs.

As the distribution voltage increases, so too does the likelihood of damaging electrical arcs. Current aerospace electrical distribution systems only protect against over current faults using either mechanical/thermal devices or sometimes solid-state switches with complex $\mathrm{I}^{2} \mathrm{~T}$ trip curves. However, these over current protective features are ineffective at detecting even high levels of intermittent electrical arcs. It is clear that a new distribution switch with arcing fault detection capabilities is going to be a key requirement for these new, high power electrical systems.

There has been much interest in the development of an arcing fault detection circuit breaker for commercial aircraft, especially following the catastrophic loss of Swiss Air flight 111 in 1998 which has been linked to an electrical fire. However, most of the research and development into these arcing fault circuit breakers has concentrated on $400 \mathrm{~Hz} \mathrm{AC}$ distribution systems found on commercial aircraft. For many of the high power space systems on NASA's roadmap, DC power systems are probably more likely.

In terms of the published research effort that has gone into arcing fault detection before and after 1998, most, if not all, have focused on $\mathrm{AC}(50 / 60 \mathrm{~Hz})$ power distribution systems. Of these, most rely on the harmonic content in the current and/or voltage signature $^{2-7}$ for fault detection and others rely on pattern recognition through Neural Networks ${ }^{2}$ or Neural Network and Fuzzy Logic combination. ${ }^{8}$ Although it is possible to detect arcing faults through either the current or voltage signature, most of these researchers have chosen to utilize only the current information. $1,2,5,7$

Since little to no work has been reported on highimpedance arcing faults to return in DC systems, the first phase of this investigation focused on evaluating

1

American Institute of Aeronautics and Astronautics

This is a preprint or reprint of a paper intended for presentation at a conference. Because changes may be made before formal publication, this is made available with the understanding that it will

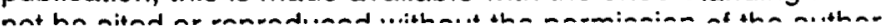


the arcing characteristics, specifically, the frequency content of the voltage and current signature, through the Fast Fourier Transform (FFT) analysis tool in a simple system. It is important to note that this research did not focus on arcing faults to chassis and low-impedance arcing faults since they can be easily detected with existing methods; such as a Ground Fault Circuit Interrupter (GFCI). The second phase addressed the issue of arc characterization and location in a radial distribution system.

\section{ARC CHARACTERIZATION}

Acquisition and analysis of the voltage and current signals of interest was done with the graphical programming software LabVIEW 6.0 in conjunction with a two-channel, 8-bit, high-speed digitizer (NATIONAL INSTRUMENTS' PCI-5112). The voltage signals were first fed through bandpass (BP) filters with corner frequencies at $400 \mathrm{kHz}$ and $30 \mathrm{MHz}$ before being sampled at 100 mega-samples per second $(\mathrm{MSa} / \mathrm{s})$. The current signals were fed through BP filters with corner frequencies at $0.16 \mathrm{~Hz}$ and $9.5 \mathrm{kHz}$ before being sampled at $50 \mathrm{kSa} / \mathrm{s}$. Isolation between the experimental system and the digitizer input was provided by a radio frequency $(\mathrm{RF})$ transformer.

\section{Single-Line System}

The single-line system (SLS), shown in Figure 1 below, is comprised of a variable power supply (POWER TEN INC., 150VDC, 44ADC), an electronic load, $\mathrm{I}_{\mathrm{L}}$, in constant-current mode (DYNALOAD, $600 \mathrm{VDC}, 200 \mathrm{~A}, 4000 \mathrm{~W}$ ), and, in parallel with the load, a $100 \Omega$ planar resistor (OHMITE) in series with an arcing fault mechanism. The $100 \Omega$ resistor is used to simulate a high-impedance arcing fault and the arcing fault mechanism was simply a mechanical vise with isolated handles and arcing contacts. The arcing contacts used for this experiment were carbon welding electrodes and the cable lengths and gauges used are shown in Table 1.

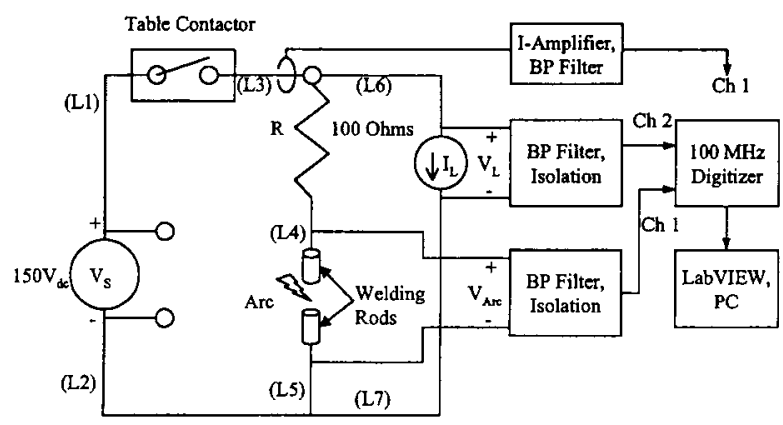

Figure 1: Single-Line Experimental System
Table 1: Cable Length and Gauge

\begin{tabular}{|c|c|c|}
\hline Cable & Length (in) & Gauge \\
\hline$(\mathrm{L} 1)$ & 46 & 10 \\
\hline$(\mathrm{L} 2)$ & 94 & 10 \\
\hline$(\mathrm{L} 3)$ & 48 & 10 \\
\hline$(\mathrm{L} 4)$ & 19.5 & 14 \\
\hline$(\mathrm{L} 5)$ & 22 & 14 \\
\hline$(\mathrm{L} 6),(\mathrm{L} 7)$ & $18+62$ & $10+1 / 0$ \\
\hline
\end{tabular}

The power supply was set at $150 \mathrm{VDC}$ and the current load was set at either $0.5 \mathrm{~A}$ or $5 \mathrm{~A}$. To induce arcing, the electrodes were manually brought together, by turning the isolated handle, and then slightly retracted. With the $100 \Omega$ resistor in series with the arc, the maximum current through the arcing path was limited to $1.5 \mathrm{~A}$.

\section{Voltage Signature}

The three voltages that were sampled and analyzed are the arc voltage, $V_{A R C}$, the load voltage, $V_{L}$, and the supply voltage, $V_{S}$. A snapshot of the arcing voltage and its corresponding spectral content is shown in Figure 2a and Figure $2 b$ for "no-fault" and "fault" condition with a load of $5 \mathrm{~A}$. Note that the magnitude of the spectral content of the arc voltage decays with frequency and frequencies above $30 \mathrm{MHz}$ are present under arcing conditions. At the sampling rate of 100 $\mathrm{MSa} / \mathrm{s}$ and 8192 samples per data set, the time difference between adjacent samples is $\Delta t$, given by

$$
\Delta t=\frac{1}{f_{s}}=10 \eta s
$$

and the spacing between adjacent frequencies, $\Delta f$, is given by

$$
\Delta f=\frac{f_{s}}{N}=12.207 \mathrm{kHz}
$$

where $f_{s}$ is the sampling rate and $N$ is the number of samples.

In a practical application, it is impossible to sense directly across the arc voltage, $\mathrm{V}_{\mathrm{ARC}}$, since the arcing fault location is unknown. However, the supply output terminals and the load input terminals provide fixed locations to sense the arcing fault. Sample plots of the arcing fault signal at the supply and load terminals are shown in Figures 3a,b. Note that the digitizer introduced a slight DC offset. The supply and load voltages were acquired simultaneously but the arc voltage was acquired separately. 


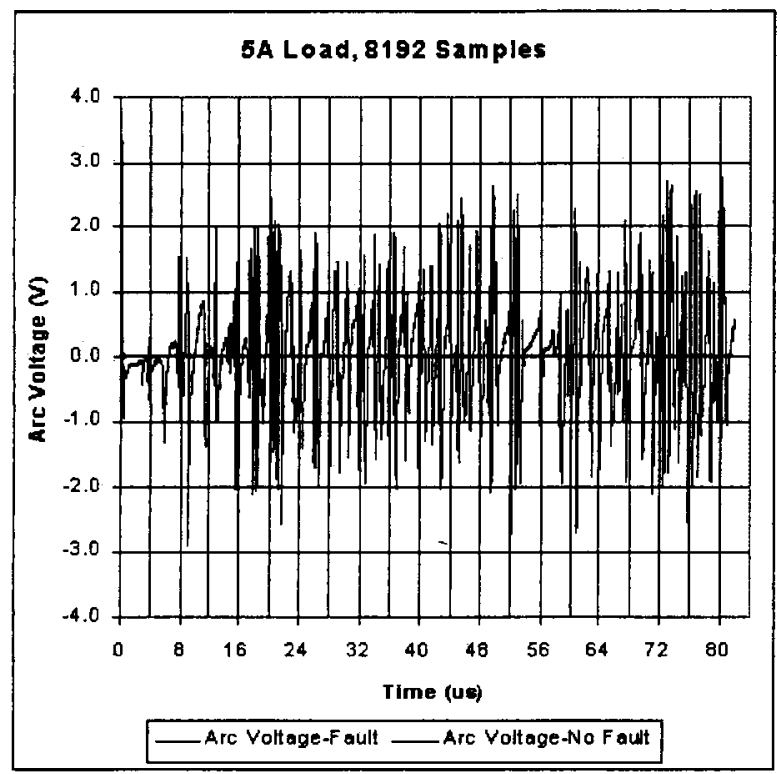

Figure 2a: Arc Voltage under No-Fault and Fault Condition

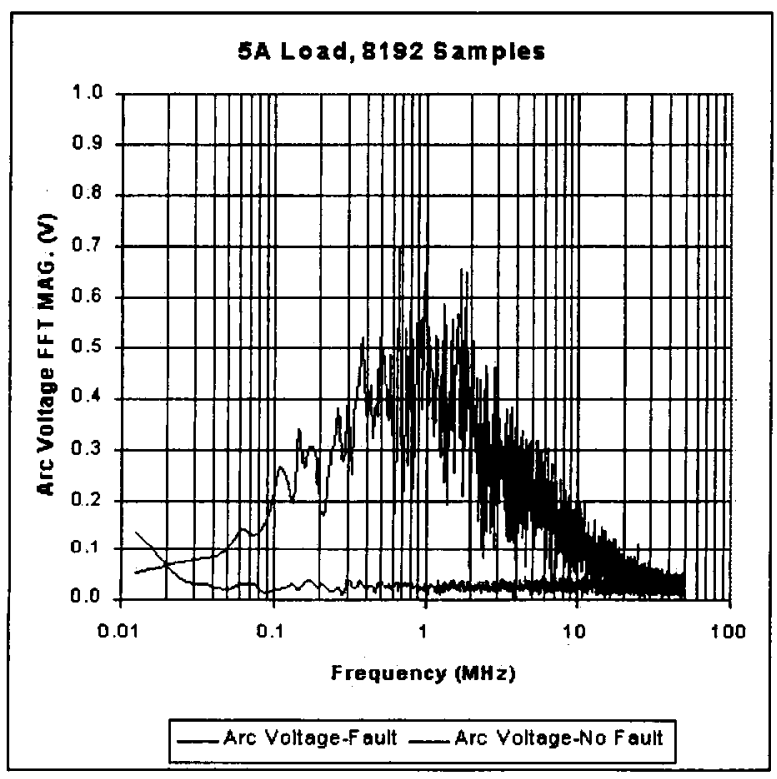

Figure 2b: Arc Voltage FFT under No-Fault and Fault Condition

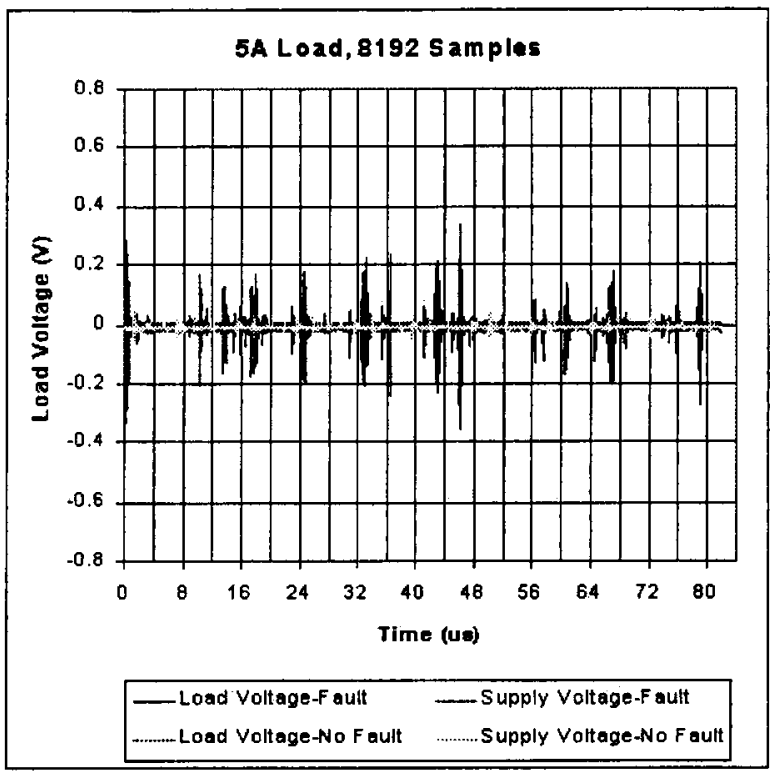

Figure 3a: Load and Supply Voltage under No-Fault and Fault Condition

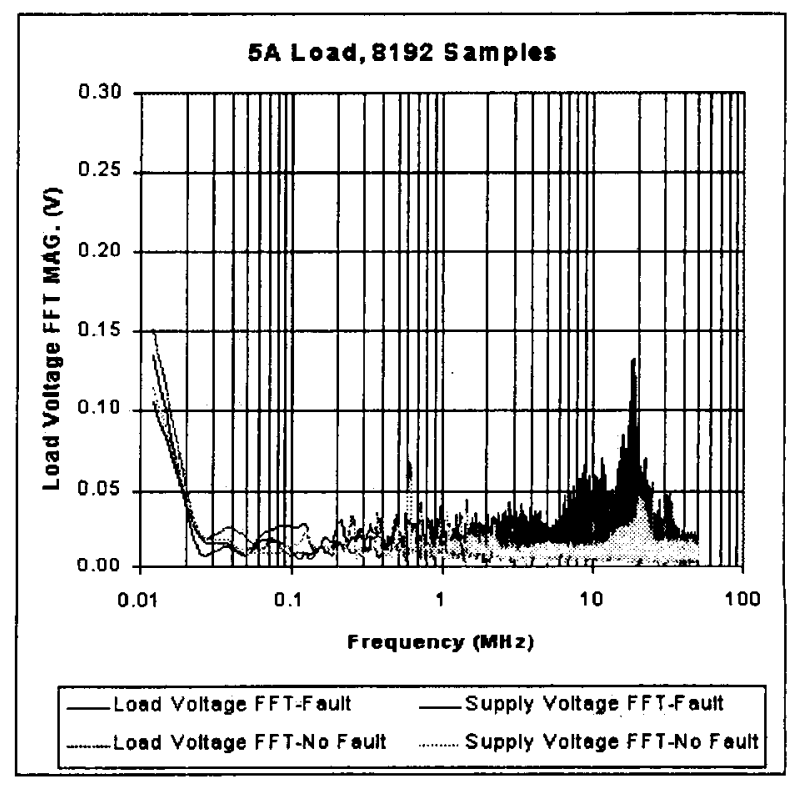

Figure 3b: Load and Supply Voltage FFT under NoFault and Fault Condition

As can be seen from the figures, the voltage signal generated by the arcing fault has been significantly attenuated by the single-line cables. Some insight into the attenuation of the signal can be obtained by measuring the frequency response of the system. Using a VENABLE Impedance Measurement System (IMS) for frequencies below $200 \mathrm{kHz}$ and an HP3577A Network Analyzer for frequencies above 200 $\mathrm{kHz}$, a frequency-dependent reference signal was 
injected at the arcing terminals and the ratio of the supply-to-reference signal and load-to-reference signal was obtained. For the supply voltage, the attenuation without the BP filter is over $30 \mathrm{~dB}$ below $30 \mathrm{MHz}$ and, for the load, it is over $16 \mathrm{~dB}$ for all frequencies (See Figure 4). Due to this inherent response of the singleline system, the arcing fault signal detected at the load or supply is mostly composed of high frequency signals centered around $19 \mathrm{MHz}$.

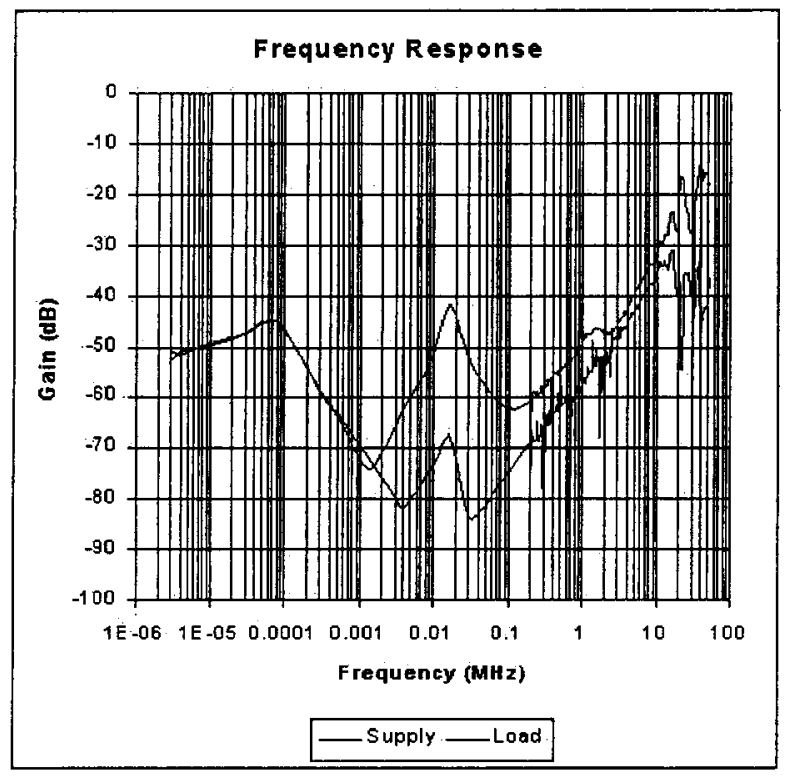

\section{Figure 4: Supply and Load Gain vs Frequency Response}

Even with this much attenuation, it was still possible to reliably detect an induced arcing fault by monitoring the frequency content around $19 \mathrm{MHz}$ of the load signal. However, as the cable lengths between the arcing fault mechanism and the sensor locations increase, the more difficult it becomes to detect the faults due to the increased attenuation.

\section{Current Signature}

In contrast to the attenuated high frequency content of the DC bus voltage, the arcing fault current signature was observed at low frequencies, with most of the frequency content below $2 \mathrm{kHz}$. Figure 5a shows two sample waveforms of the current, one under nofault and the other under fault, and Figure $5 \mathrm{~b}$ shows their corresponding FFT plots. With the sampling parameters of $50 \mathrm{kSa} / \mathrm{s}$ and 8192 samples, $\Delta \mathrm{t}=20 \mu \mathrm{s}$ and $\Delta \mathrm{f}=6.104 \mathrm{~Hz}$.

Taking the same approach as with the voltage, an induced arcing fault could also be reliably detected by monitoring the frequency content below $2 \mathrm{kHz}$.

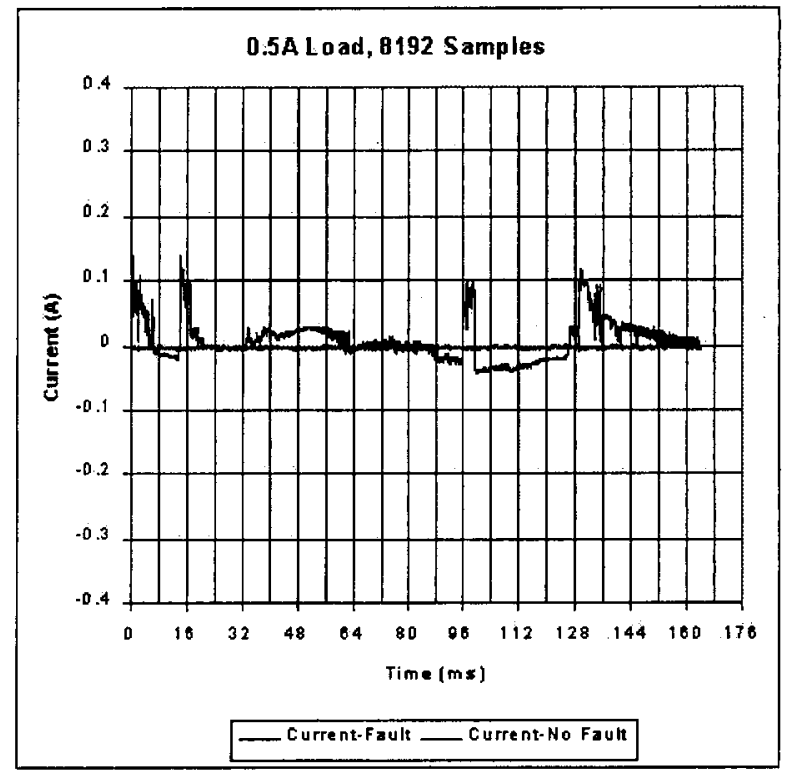

Figure 5a: Current under No-Fault and Fault Condition

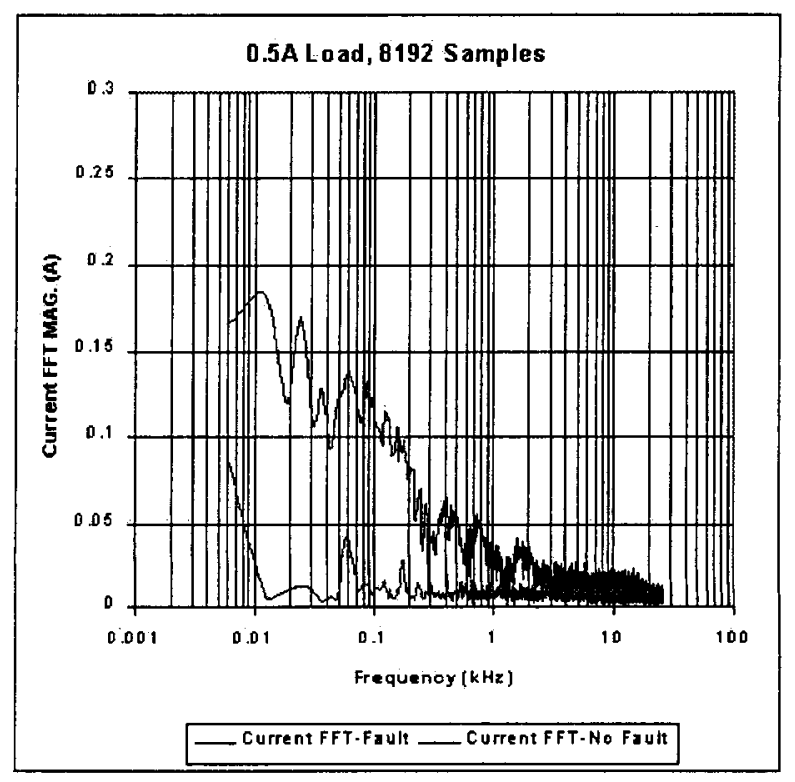

Figure 5b: Current FFT under No-Fault and Fault Condition

\section{ARC LOCATION}

Having established that it is possible to detect an arcing fault by monitoring the $\mathrm{AC}$ content in the $\mathrm{DC}$ bus voltage or the DC system current, the next task was to address the location of the arcing fault in a multi-line system, such as a Radial Distribution System (RDS). 


\section{Radial Distribution System}

The multi-line system used in this investigation is the two-channel RDS shown in Figure 6 below with the cable lengths and gauges shown in Table 2. As before, the DC supply was set at $150 \mathrm{~V}$ and the arcing impedance was fixed at $100 \Omega$. The current load on channel 1 was set at either $0.5 \mathrm{~A}$ or $5 \mathrm{~A}$ and the resistive load on channel 2 was set at $50 \Omega$. The arcing fault was induced on channel one and the voltage in each channel was sensed at the output of the CRYDOM (500VDC, $10 \mathrm{~A}$ ) solid-state relay (Sw1, Sw2) and the return bus; the currents were sensed as shown.

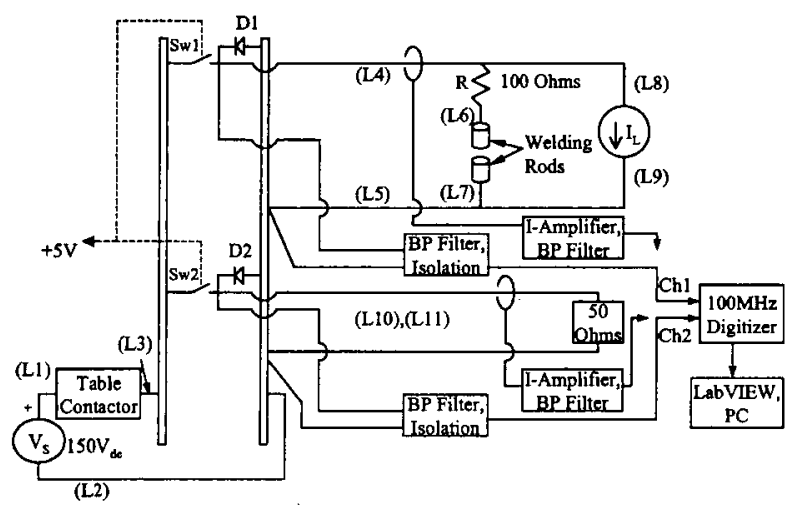

Figure 6: Two-Channel Radial Distribution System

Table 2: Cable Length and Gauge of RDS

\begin{tabular}{|c|c|c|}
\hline Cable & Length (in) & Gauge \\
\hline$(\mathrm{L} 1)$ & 46 & 10 \\
\hline$(\mathrm{L} 2)$ & 73.5 & 10 \\
\hline$(\mathrm{L} 3)$ & 27.5 & 10 \\
\hline$(\mathrm{L} 4)_{1}(\mathrm{~L} 5)$ & 53 & 12 \\
\hline (L6) & 19.5 & 14 \\
\hline (L7) & 22 & 14 \\
\hline$(\mathrm{L}),(\mathrm{L} 9)$ & $18+62$ & $10+1 / 0$ \\
\hline (L10). (L11) & 60 & 12 \\
\hline
\end{tabular}

$\underline{\text { Results }}$

\section{Voltage}

For the RDS under investigation and with Swl and Sw2 closed, the input terminals of the BP filters of channel 1 and channel 2 are effectively tied to the same points. Based on the gain-versus-frequency response plot in Figure 7, the voltage seen by the BP filter of channel 2 will have little to no attenuation compared to the voltage seen by the BP filter of channel 1 between $20 \mathrm{kHz}$ and $10 \mathrm{MHz}$. However, as with the SLS, the lower frequencies (below $100 \mathrm{kHz}$ ) are highly attenuated but, in contrast to the SLS, frequencies above $1 \mathrm{MHz}$ exhibit a maximum attenuation of $\sim 30 \mathrm{~dB}$ versus $\approx 50 \mathrm{~dB}$ for the load voltage of the SLS. This is the reason why most of the arcing fault signature is now centered around 4-5 $\mathrm{MHz}$ (See Figures 8a,b). What accounts for the different attenuation levels is the cable impedance between the voltage sensors, the load, and supply in the RDS.

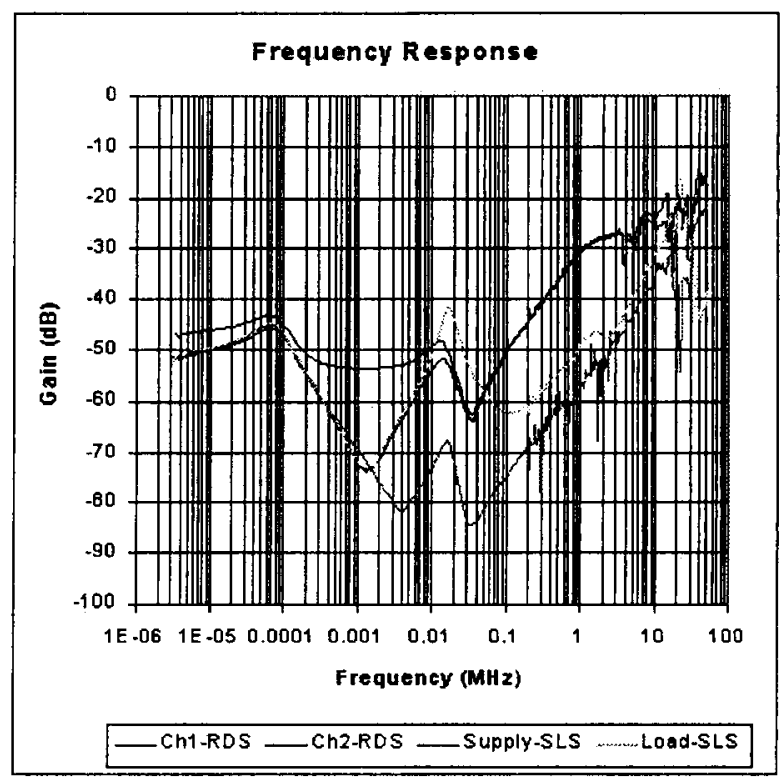

Figure 7: SLS and RDS Gain vs Frequency Response

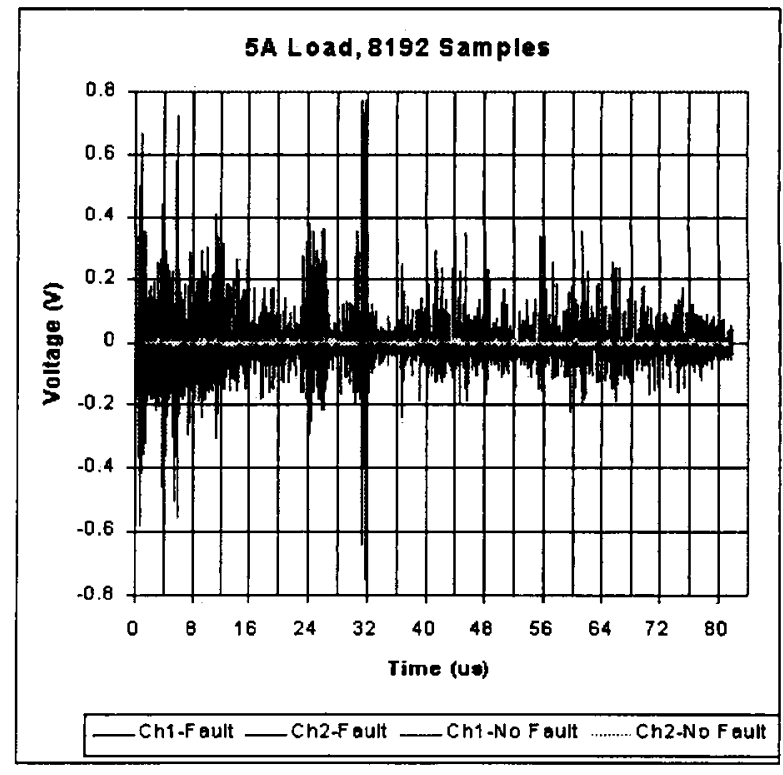

Figure 8a: Ch1 and Ch2 Voltage under No-Fault and Fault Condition 


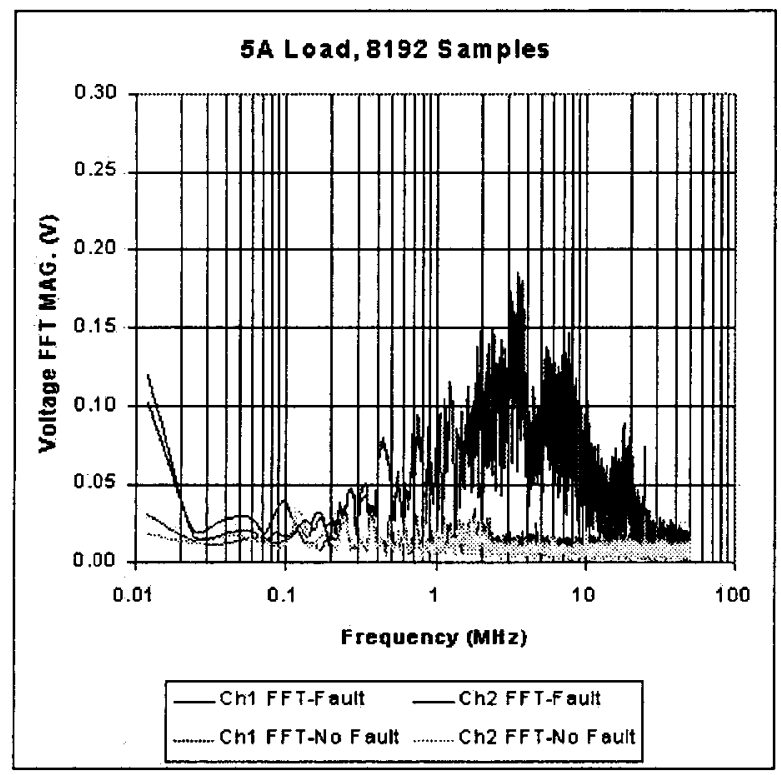

Figure 8b: Ch1 and Ch2 Voltage FFT under NoFault and Fault Condition

Since the voltage signature is detected with virtually equal amplitude and frequency content by both voltage sensors, it is not possible to use the voltage information for arc location in a RDS as shown in Figure 6. However, it is possible to isolate the channels, if desired, by inserting an LC filter in each channel, as shown in Figure 9; the voltage and corresponding FFT of channel 1 and channel 2 are shown in Figure 10a and Figure 10b. This approach not only enables fault location through the voltage signature but it also reduces the attenuation of the voltage signature at the sensors (compare the first two plots in Figure 11), making it possible to detect arcing faults further away from the DC bus. Unfortunately, as Figure 11 shows, the attenuation of the voltage signature, for frequencies of interest but below $3 \mathrm{MHz}$, at the sensors increases as the length of cables (L4) and (L5) increase.

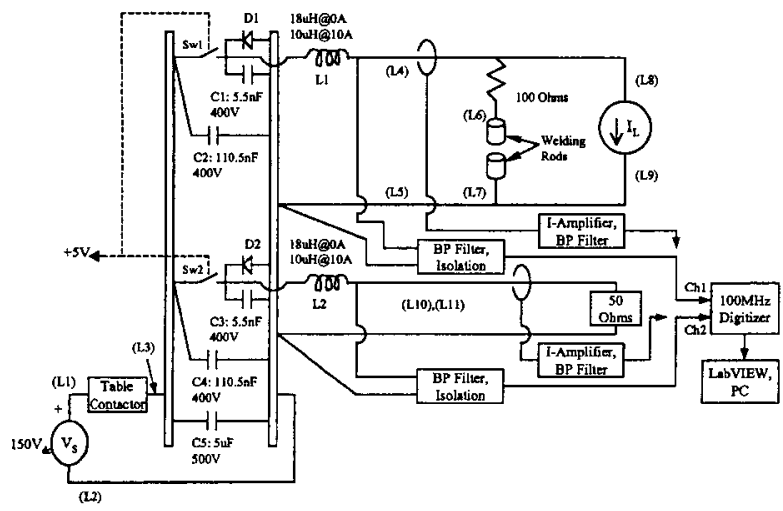

Figure 9: Radial Distribution System with LC Filter
Furthermore, at frequencies above $3 \mathrm{MHz}$, the parasitic inductance in the system, including the inductance of the cables, comes into play, resulting in an unpredictable frequency response. Yet another drawback at these high frequencies is the significant increase in transmitted energy above $3 \mathrm{MHz}$, thereby making it difficult if not impossible to detect the location of an arcing fault through the voltage signature as the cable length increases beyond $50 \mathrm{ft}$.

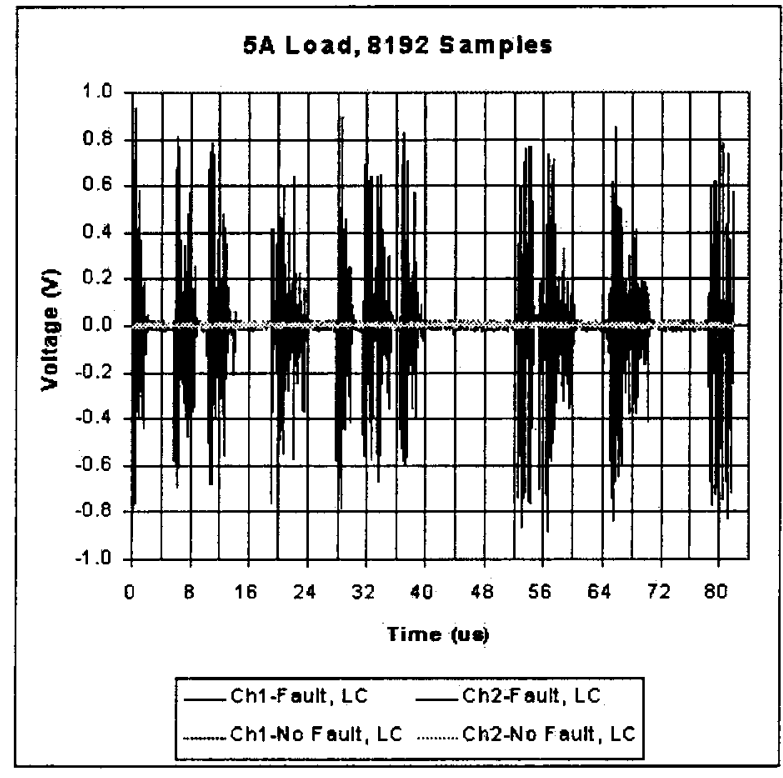

Figure 10a: Ch1 and Ch2 Voltage for RDS with LC Filter

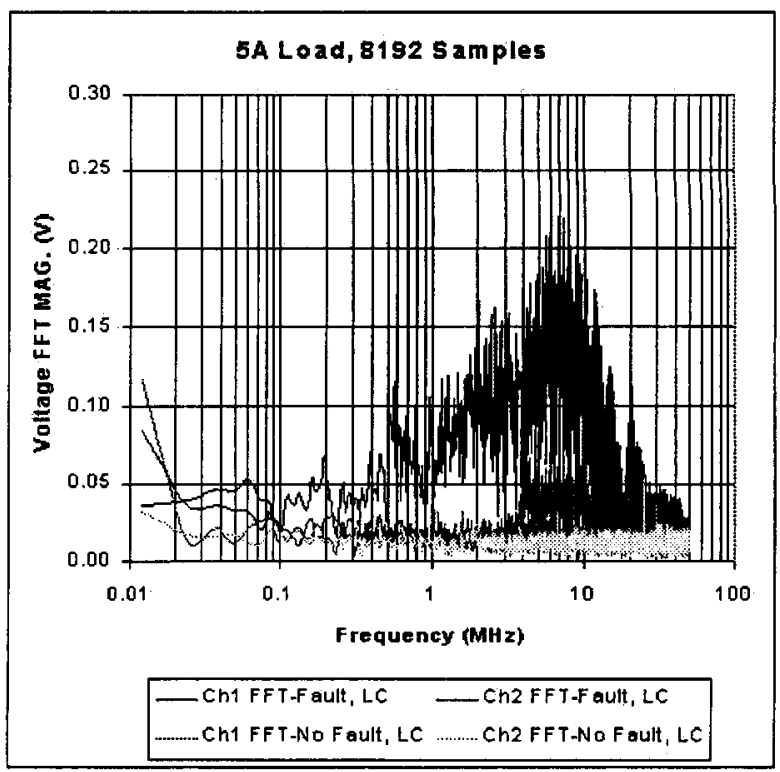

Figure 10b: Ch1 and Ch2 Voltage FFT for RDS with LC Filter 


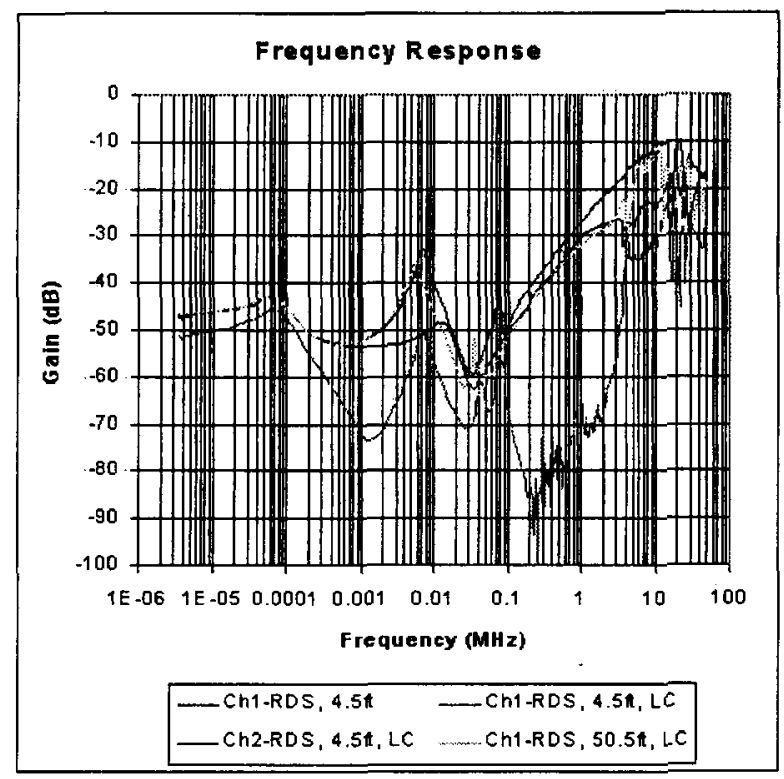

Figure 11: RDS Gain Response vs Cable Length and LC Filter

\section{Current}

A better approach to accomplish arc location is to utilize the current signature, since it is inherently localized and the low frequency arcing fault signature is not affected by the cable length, as is the case with the high frequency voltage signature. Figures $12 a$ and $b$ show the results for the RDS in Figure 6; that is, with no LC filter.

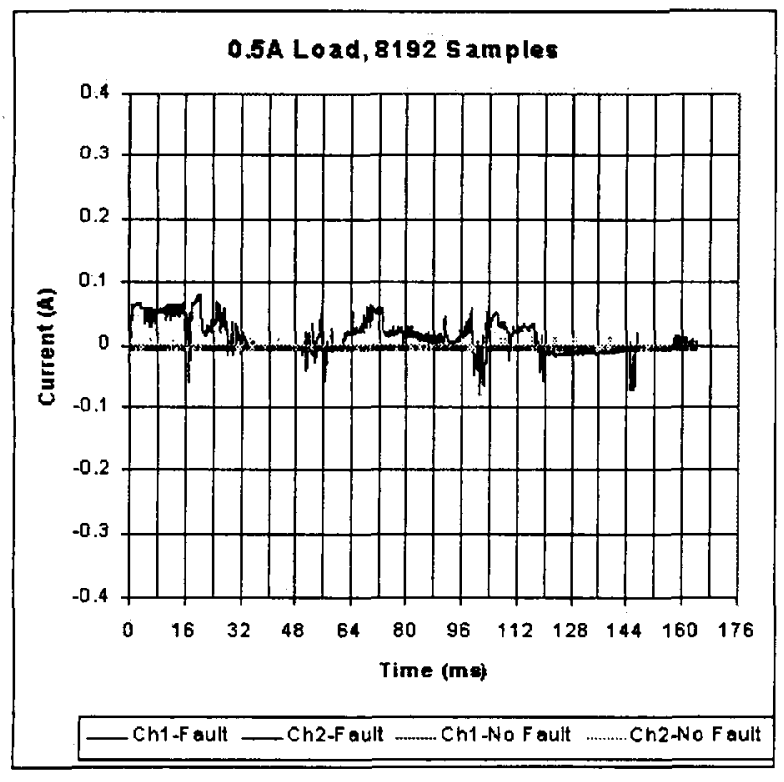

Figure 12a: Ch1 and Ch2 Current under No-Fault and Fault Condition

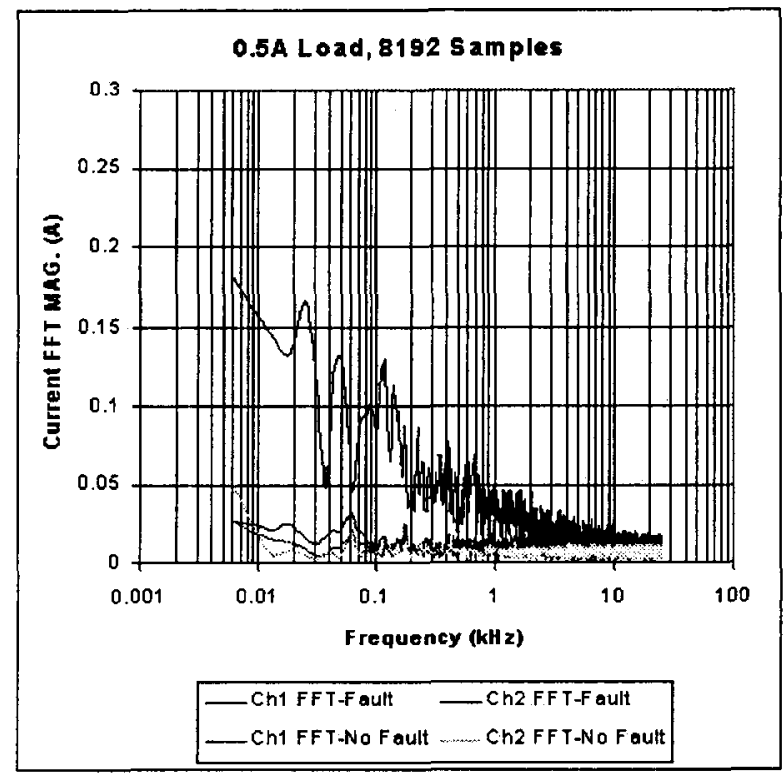

Figure 12b: Ch1 and Ch2 Current FFT under NoFault and Fault Condition

One of the issues that arise is whether the low frequency current signature and the high frequency voltage signature are always generated simultaneously. Based on observation, the answer is no. Sometimes they are both present and sometimes only the low frequency current signature or the high frequency voltage signature is present. Figure 13 shows a sample result obtained by sampling at $50 \mathrm{MSa} / \mathrm{s}$ and taking 131,072 samples per code loop. In each code loop, the sampled

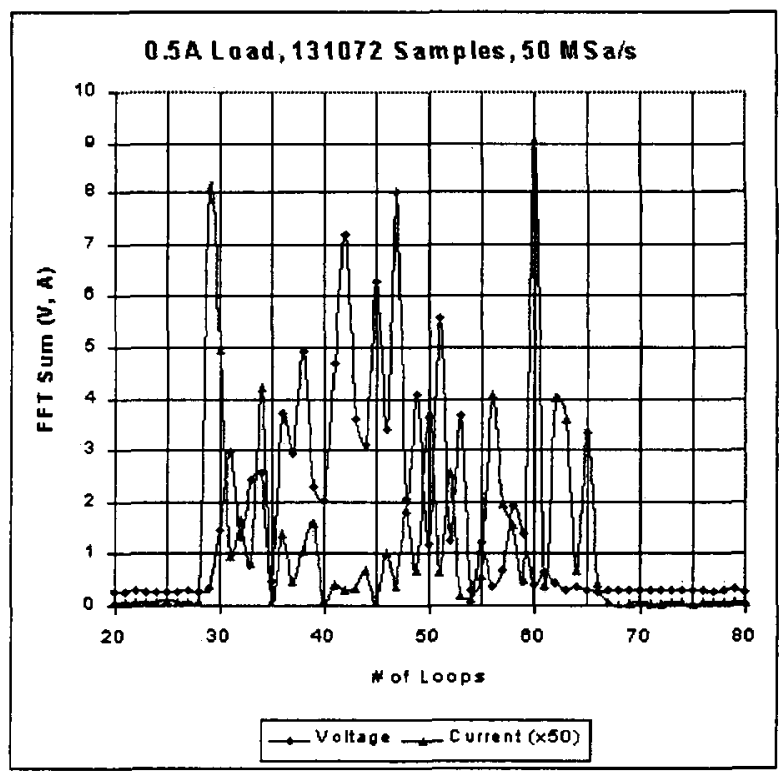

Figure 13: FFT Sum for Voltage and Current 
data is analyzed and an FFT sum is generated. At these settings the minimum frequency resolved is only 381.47 $\mathrm{Hz}$. In Figure 13 the sum of the discrete frequencies present between $5 \mathrm{MHz}$ and $7 \mathrm{MHz}$ is plotted for the voltage and between $381.47 \mathrm{~Hz}$ and $1907.35 \mathrm{~Hz}$ for the current. Since only 5 discrete frequencies were summed for the current, the result was multiplied by 50 for easy comparison to the voltage sum.

\section{CONCLUSION}

This research has thus far shown that laboratory induced arcing faults, under the conditions described above, generate a considerable amount of $\mathrm{AC}$ voltage across the arc with frequencies above $30 \mathrm{MHz}$, but, for the two systems investigated, most of the voltage signature is significantly attenuated. Of the two systems, the radial distribution system exhibits significantly less attenuation for frequencies above 100 $\mathrm{kHz}$. Because of this inherent response in the systems, the detectable arcing fault voltage signature was in the $\mathrm{MHz}$ range, requiring high-speed data acquisition to implement an arcing fault detection algorithm.

In order to implement arc location in a radial distribution system via the voltage signature, it was necessary to isolate the channels; this was done by inserting a small LC filter in each channel. This approach is fairly successful for relatively short, unshielded cables ((L4),(L5)) of lengths less than $50 \mathrm{ft}$.

In contrast to the voltage, the current signature is at relatively low frequencies. With this information, an arcing fault can be detected and located with no modifications to the system and the length of the cables does not affect this information. It just follows then that the current signature would be the better choice.

However, since the arcing fault signature manifests itself at such different frequency ranges, a simple test showed that both signatures are not always present at the same time. This leads to a preliminary conclusion that it might be necessary to monitor both the current and voltage signature but, keeping in mind the limitations of the voltage signature, less confidence would have to be placed on the latter.

All the results presented thus far were obtained with a constant current electronic load and resistive load. Future work will focus on improving the robustness of the detection algorithm to distinguish between transient arcing conditions, such as a relay closing or opening, or arcing-loads, such as DC brush motors, and a true arcing fault. At this juncture, all the signal processing and analysis is done digitally in a high-powered data acquisition system. Clearly, this is not a practical solution, but work has been initiated on a standalone, mixed-signal analog/digital approach.

\section{REFERENCES}

1. A. F. Sultan, G. W. Swift, and D. J. Fedirchuk, "Detection of High Impedance Arcing Faults using Multi-Layer Perceptron", IEEE Transactions on Power Delivery, Vol. 7, No. 4, October 1992, pp. $1871-1877$.

2. Dogan Gökhan Ece, Francis M. Wells, and Hakan G. Seken, "Analysis and Detection of Arcing Faults in Low-Voltage Electrical Power", $7^{\text {th }}$ Mediterranean Electrotechnical Conference, Vol. 3, 1994, pp. $929-935$.

3. Dogan Gökhan Ece, "Behavior of System Voltage during Arcing Faults and Switching Events", Proceedings of the Mediterranean Electrotechnical Conference, Vol. 2, 1996, pp. $757-760$.

4. V. V. Terzija, Z. M. Radojevic, M. B. Djuric, "A New Approach for Arcing Faults Detection and Fault Distance Calculation in Spectral Domain", IEEE Proceedings of the Transmission and Distribution Conference, 1996, pp. 573-578.

5. Carl L. Benner and B. Don Russell, "Practical High-Impedance Fault Detection on Distribution Feeders", IEEE Transactions on Industry Applications, Vol. 33, No. 3, May/June 1997, pp. $635-640$.

6. K. J. Zoric, M. B. Djuric, and V. V. Terzija, "Arcing Faults Detection on Overhead Lines from the Voltage Signals", Electric Power \& Energy Systems, Vol. 19, No. 5, 1997, pp. $299-303$.

7. Jincheng $\mathrm{Li}$ and Jeffrey L. Kohler, "New Insight into the Detection of High-Impedance Arcing Faults on DC Trolley Systems", IEEE Transactions on Industry Applications, Vol. 35, No. 5, September 1999, pp. $1169-1173$.

8. Patricia R. S. Jota and Fábio G. Jota, "Fuzzy Detection of High Impedance Faults In Radial Distribution Feeders", Electric Power Systems Research, Vol. 49, 1999, pp. 169- 174. 